\title{
A New Literacies Approach to Academic Numeracy Practices in Higher Education
}

\author{
ROBERT PRINCE and ARLENE ARCHER
}

\begin{abstract}
This paper explores the terms 'mathematical literacy', 'quantitative literacy' and 'numeracy', in order to gain theoretical clarity on their meanings and the ways in which they are used. The teaching-learning situation and the learner are constructed in particular ways by these terms, and different understandings of these terms may reflect the values and rationales of various stakeholders who promote them. We propose the term 'academic numeracy practices' in order to emphasise the socially situated nature of all practices, to avoid reifying 'numeracy' into a set of discrete skills that an individual can either possess or lack, and to avoid extending the characteristics of one mode (namely, writing) to other modes. In arguing for the new term, we draw on the theoretical orientation of New Literacies Studies and multimodality. We exemplify our position by looking at charts as conventionalised practice in Higher Education in South Africa, focusing on BMI charts in the Health Sciences.
\end{abstract}

\section{Introduction}

This paper has two related focus areas. The first is to explore the terms 'mathematical literacy', 'quantitative literacy' and 'numeracy' in order to gain theoretical clarity on the meanings of these terms and the ways in which they are used. Attempts at definitions can reaffirm the emergence of a new area of study, but can also indicate cross-fertilisation of different theoretical paradigms. In South Africa at the moment, 'numeracy', 'mathematical literacy', 'quantitative literacy' and mathematics are topical terms. 'Mathematical literacy' has been introduced as an alternative subject to mathematics in the final three grades in South African schools. This has raised issues for debate in various educational arenas, including programmes in tertiary institutions where the controversy has focused on performance in Mathematics as the criterion for admission.

The second focus area is an exploration into the applicability and transferability of theories from New Literacies Studies (NLS) in order to theorise the use of a new term, namely 'academic numeracy practices'.

Along with theorists such as Brian Street (2005), we examine terms derived from NLS to draw an analogy between numeracy and literacy. Street, Baker and Tomlin (2002) use notions within NLS to explore the relationship 
between acquisition and formal learning, and between 'home' numeracy practices and 'school' numeracy practices. Here 'home' is often socially or culturally situated, such as rural India (Street, Rogers and Baker 2006), and 'school' deals with the Mathematical classroom. We are also interested in the quantitative resources that students bring from a range of contexts, but in contrast to these theorists, our educational context focuses on Higher Education, rather than secondary schools.

In looking at New Literacies Studies, we also focus on the 'multimodality' of all meaning-making. By this we mean the increasing multiplicity and integration of modes of meaning making, including, the audio, the spatial, and the gestural (Kress and Van Leeuwen 1996, Kress 2000, Stein 2003, the New London Group 1996). A 'multimodal' approach to pedagogy and to theorising communication recognises the different semiotic dimensions of representation and their inter-connection. Utilising a range of modes is one way of harnessing the diverse representational resources, including quantitative, that students bring with them (Archer 2006, Stein 2003). Theorists such as Street and Baker (2006), Archer, Frith and Prince (2002), Bezemer and Kress (2007) have begun to illustrate and apply views of multimodality to theorising numeracy practices, but this has not been done in any depth yet. We are particularly interested in looking at the use of the visual in academic disciplines, and in this paper focus on the use of charts as conventionalised multimodal texts within the Health Sciences.

\section{Problematising terms}

The three main terms currently circulating in the literature and in practice include 'mathematical literacy', 'quantitative literacy' and 'numeracy'. 'Mathematical literacy' and 'quantitative literacy' are often used interchangeably. The South African Department of Education, National Curriculum statement uses the term 'mathematical literacy', and describes it in the following way:

Mathematical Literacy provides learners with an awareness and understanding of the role that mathematics plays in the modern world. Mathematical Literacy is a subject driven by life-related applications of mathematics. It enables learners to develop the ability and confidence to think numerically and spatially in order to interpret and critically analyse everyday situations and to solve problems. (Department of Education 2003:9)

Perhaps differently to 'mathematical literacy', the term 'quantitative literacy' includes statistics in its subject area. However, both of these terms rely on the concept of 'literacy', which we argue is a theoretically and 
politically contested term, and should thus be questioned and problematised.

There is the common-sense understanding of the term 'literacy', as referring to reading and writing, particularly in the school setting. This is what Street (1995) refers to as the 'autonomous' view of literacy, namely the view that literacy has cognitive effects apart from the contexts in which it exists and is used. This understanding of the term is often used in conservative arguments about the 'literacy crisis', the poor state of the education system, and the decline of the English language. To counter this view of literacy, the New Literacy Studies attempts to give a social practices account of literacy, where the term 'literacies' refers to any form of social communication or practice that requires a semiotic code. This view of literacy as social practice, argued by, among others, Heath (1983), Street (1995), Baynham (1995), Barton and Hamilton (1998) and Gee (1996), Baynham and Baker (2002), engages with diverse notions of reading and writing that are emerging from current social and technological changes. To be 'literate' then does not simply mean having acquired the technical skills to decode and encode signs, but having mastered a set of social practices related to a set of signs which are inevitably plural and diverse. This is what Street refers to as the 'ideological model' of literacy $(1984,1995)$ where literacy learning involves learning particular roles, forms of interaction, and ways of thinking. According to the ideological view, there are many literacies, linked to the social institutions in which they are embedded. 'Literacies' are therefore understood as multiple, socially situated and contested. The spirit behind the pluralising is an attempt to value what particular groups in society are doing and, in this sense, it is a political move. We, however, query the theoretical clarity of the pluralising move, which becomes even more theoretically complex when the term 'literacy' gets extended to include notions of mathematical competence.

In contrast to this inclusive view of 'literacy', Gunther Kress, in his later theoretical work, moved away from the New Literacies Studies position to oppose the use of the term to encompass all modes (2003:23-25). He argues against extending metaphors from language to other forms of representation, and defines literacy as a label for 'lettered representation'. By using a homogenising term like 'literacy', he argues, the characteristics of one mode are extended across the others, precluding certain questions and tending to reify literacy into skills. What is most worrying about the use of a term like 'literacy' from an educational point of view is that it passes implicit value judgements where literacy is used as a metaphor for competence (as in 'emotional literacy' or 'cultural literacy'). This is often how the term is used in everyday speech.

The term 'numeracy' has been problematised by amongst others Coben (2003), FitzSimons et al (2003), Swain et al (2005), Gal et al (2005). 
We wish to focus on three problematic aspects of the term. Firstly, the term does not capture the inextricable link between language and mathematics. Kress (2003: 23) makes a three-way distinction in naming practices: naming the mode or resources for representing (writing, numbers), naming the mode in use (literacy, numeracy) and naming the means of dissemination (book, website). This distinction is somewhat problematic, as it seems not to include the mode of writing in 'numeracy', which he defines solely as the use of numbers. However, in a given context, numbers do not exist on their own they are always embedded in language. The number 60 becomes more meaningful, when it is stated as $60 \mathrm{~kg}$, for instance. Also, we cannot count water without introducing something discrete with which to measure it, such as 'five cups of water' or 'five gallons of water'. Ascher (1991:5) reflects on the inter-relation between numbers and language:

Our written words, one, two, three, and so on, are symbols that represent the sounds of the spoken words; we also represent numbers by the written symbols $1,2,3 \ldots$ We say the word two when we encounter the letter combination t-w-o or the symbol 2, but we do not need these symbols to know or use the spoken word.

Chapman and Lee (1990) also talk of the importance of the use of language in mathematics and give the words 'fertility' and 'mortality' as examples. These might be classified as "signifying rates of change, numbers of births and deaths, cultural patterns or personal experiences, each requiring very different reading operations to be carried out" (1990: 283). Given these considerations, we can critique the notion of separating numbers and language by looking at graphical representations such as charts. Charts represent numbers, but comprise all three modes, namely, numbers, writing, visuals.

The second issue with the term 'numeracy' is that, like the terms 'mathematical literacy' or 'quantitative literacy', it implies 'competence'. Interestingly, numeracy has connotations of very basic levels of proficiency, whereas literacy has developed connotations of increased competence, such as 'emotional literacy'. Thirdly, 'numeracy' often refers to workplace practices, and indexes an adult education environment (Jablonka 2003).

\section{The concept of 'academic numeracy practices'}

We propose the term 'academic numeracy practices' to foreground the connection to the disciplines of mathematics and statistics in the first instance and language in the second. Centrally, we are concerned with the practices in which these competencies are required. 'Practice' offers a way of linking semiosis with what individuals as socially situated actors do, both at the level of context of a specific situation and at the level of context of 
culture. The term 'practice' is defined as 'habitualised ways, tied to particular times and places, in which people apply resources (material or symbolic) to act together in the world' (Chouliaraki and Fairclough 1999: 21). Bourdieu (1977: 78) suggests that a practice is an action with a history. This notion of 'practice' has been applied to numeracy by a number of theorists such as Street $(2000,2005)$ and Baynham and Baker (2002). For these theorists, numeracy practices are:

more than the behaviours that occur when people 'do' mathematics / numeracy, more than the events in which numerical activity is involved, and so enable the conceptualisations, the discourses, the values and beliefs and the social relations that surround numeracy events as well as the contexts in which they are sited to be explored (Baynham and Baker 2002:6).

As opposed to a skills-based view of student learning, a practices view is not a deficit view. In curriculum design, we cannot ignore the current South African and global context, and looking at numeracy as a social practice could be a way of including aspects that were traditionally sidelined by mainstream curricula, such as indigenous knowledge systems and ethnomathematics, for instance. Ethnomathematics is defined as 'the study of the mathematical ideas of nonliterate peoples' (Ascher and Ascher 1986: 125), although there is a broad range of perspectives within its terrain. It has broadened the history of mathematics by imbuing it with a multicultural, global perspective. It recognises that belief in the universality of mathematics can limit one from considering that different ways of thinking may lead to radically different ways of counting, ordering, sorting, measuring, inferring, classifying, and modelling. According to D'Ambrosio (1997:6):

once we abandon notions of general universality, which often cover for Eurocentric particularities, we can acquire an anthropological awareness: different cultures can produce different mathematics and the mathematics of one culture can change over time, reflecting changes in the culture.

What is extremely valuable about the ethnomathematics movement is that it invites us to look at how knowledge was built throughout history in different cultural environments. It involves a comparative study of techniques and modes, of explaining and understanding. These aspects of knowledge are usually studied in isolation and are identified with disciplines like history, sociology, education. The holistic approach taken by ethnomathematics is useful for our notion of 'academic numeracy practices' as we too look at the interrelations of all these disciplines in the analysis of knowledge. 
However, although the concept of 'academic numeracy practices' is inclusive of ethnomathematics, it is not equivalent to it. It is clear that mathematical ideas take shape within particular contexts and different cultural groups have distinct ways of reasoning, of measuring, coding and classifying, including academic mathematicians. However, it does seem to us that both New Literacies Studies and ethnomathematics are political projects, taking place at a particular point in history. We need to be critical of them and move one step beyond these historical moments. Both approaches seem to reify culture to an extent by linking specific practices to specific groups in more or less deterministic ways. A criticism could be that the terrain of ethnomathematics is circumscribed and limited to the mathematical ideas of 'nonliterate', non-Western peoples (Powell and Frankenstein 1997). Curriculum development in developing countries requires a more global and clearly holistic approach. Perhaps Kress's notion of 'representational resources' is a more productive one here.

'Representational resources' imply agency and potential, rather than a concept such as 'home' literacies which implies a boundedness in time and space. A notion of home literacies assumes a distinct difference between school, home and university, plus a particular linear timeline of literacy practices, which are in fact more fluid. The notion of 'representational resources' is more inclusive and covers both home practices and past schooling practices.

In conceptualising the term academic numeracy practices, it is worth noting some of the differences between mathematics and academic numeracy practices. Firstly, mathematics requires students to enter the realm of abstraction which rises above context, whereas academic numeracy requires students to stay in context. Secondly, mathematics is about general principles that can be applied to a range of contexts while a focus on academic numeracy practices sees every context through a quantitative lens. Thirdly, statistics is the quantitative tool that is closer to academic numeracy practices than to traditional school mathematics (see Hughes-Hallet 2001). From the above characterisation, it is clear that more mathematics does not necessarily lead to an improvement in academic numeracy practices.

\section{Charts as situated social practice}

In order to exemplify our notion of practice in Higher Education, we look at a common representational form, namely charts. Charts are employed as a rhetorical means in publications to both construct phenomena and provide proof of phenomena. They are used as a means of analysing data (often in real world contexts) and to communicate information about these data. Charts allow for the quantification of aspects of humans, such as age, sex, weight, length, head circumference, stature, and the use and creation of ratios and indices, such as Body Mass Index 
(BMI), that relate to their physical growth. Data on its own is not very useful until it has been used to create 'information'. Statistics can be used to make sense of data, including notions such as mean, median, range, percentiles, quartiles, inter quartile range, standard deviation and tables, and graphical representations, such as bar charts, scatter plots, line graphs.

Our premise is that charts (and their written or spoken subtexts) are multimodal texts that are read by individuals of varying backgrounds. Roth and Bowen (2001) identify two difficulties that students have in reading charts. The first is difficulty with the structuring process, namely identifying aspects that signify, and the second, difficulties with the process of grounding signs in the world (2001:185). We agree with Roth and Bowen that graphs contain little circumstantial information to ground signs in the world in order to recreate the situation on which the chart is based. Because charts, like other sign forms, have arbitrary but conventional relations to the things they represent, one cannot elaborate their content without knowing these conventions.

An orientation toward charts as social practice avoids a deficit approach to student graphing-related activities. Take the following scenario as an example. A student is faced with a graph that is increasing from left to right. When asked about the graph, she replies that it is decreasing. Upon being questioned about this she uses her finger to trace the graph from right to left to confirm that it is decreasing. She clearly understands what it means for a graph to decrease (and presumably increase), but does not fully understand the convention of reading graphs from left to right. In Archer, Frith and Prince (2002) we examined an example of a student poster showing HIV/AIDS infection rates. The students chose from a range of semiotic resources to produce a message deemed appropriate for a particular audience. Although, it was not completely accurate mathematically, the visual representation of the data had a specific impact. It managed to put a human face to the talk about statistics. This human face is important in a discussion about HIV / AIDS where numbers can easily become a distancing mechanism from the issue. Both of these examples demonstrate the importance of understanding what resources students bring to their graphicacy practices, and the importance of working with these in the curriculum.

\section{BMI charts in Health Sciences}

The understanding of growth and BMI charts (see Figure 1) is important in screening and monitoring growth in individuals and populations, and is thus vital knowledge for prospective Health Science professionals. In Prince and Archer (2006) we look at how growth charts, with considerable limitations and based on small and unrepresentative samples, are largely developed in the United States but have been used in 
South Africa since the early 1900s. In 2000 South Africa had an infant mortality rate of 59 per 1000. Infant Mortality rate refers to the number of children less than one year old who die in a year, per 1000 live births during the year. We also had an under five mortality rate of 100 per 1000. Under five mortality rate refers to the percentage of children born who die before the age of five, per 1000 live births during the year. Even though HIV/AIDS was the leading cause of death among young children, accounting for 40 percent of the deaths in 2000, low birth weight, diarrhoea, lower respiratory infections and protein energy malnutrition accounted for a further 30 percent of the childhood deaths.

In the chart for the BMI of boys from two to 20 years in Figure 1 it is tempting to interpret the individual line charts as the BMI of an individual. However, the line charts are lines connecting the BMI values for the same percentiles of different age groups, so that the fifth percentile for the four year age group is $14 \mathrm{~kg} / \mathrm{m} 2$, where the fifth percentile for the BMI value of 17,5 year olds is $18 \mathrm{~kg} / \mathrm{m} 2$.

Data from the measurement and study of the human body and its parts and capacities are valuable indicators of attained size and physical growth in children and adults. In looking at Body Mass Index charts as situated social practice, it is interesting to look at the history of these charts. The Body Mass Index of a person is determined by measuring the Weight (in $\mathrm{kg}$ ) and Height (in $\mathrm{m}$ ) and calculating weight over height to the power of two and then comparing this value (in kilograms over metre squared to the values that have been determined, by statistical means, for their age and sex either in a table or on a chart. In an attempt to unpick the use of this particular measure amongst Health Science students and professionals it soon became clear that the reasons for using this ratio are by no means well understood by them and yet it is such a pervasive practice within this discipline, as well as in everyday life. For a time we could not find a ready reference to where this measure was first introduced and finally found a reference to a facsimile reproduction of the 1842 English translation of a book by Quetelet (1969), A treatise on man and the development of his faculties. Quetelet had recorded various body measurements in an attempt to look for patterns within and between the measurements. This is a statistical rather than mathematical approach. A statistical approach tends to be more comfortable with uncertainty, whereas a mathematical approach often assumes something inherent in the phenomenon itself, such as an underlying equation. To decide on such a measure requires one to make various assumptions, about the 'normal person' and the ratios of various body measurements that will be a proxy for this 'ideal' person. It is interesting to question which ratio would provide a proxy for this 'normal' person, for instance, whether weight over height or any other ratio using Weight and Height to various powers would give a similar or better proxy for this 'ideal'. 
Quetelet (1969) somewhat arbitrarily uses the ratio weight over height and it is only later that the current BMI ratio came into use.

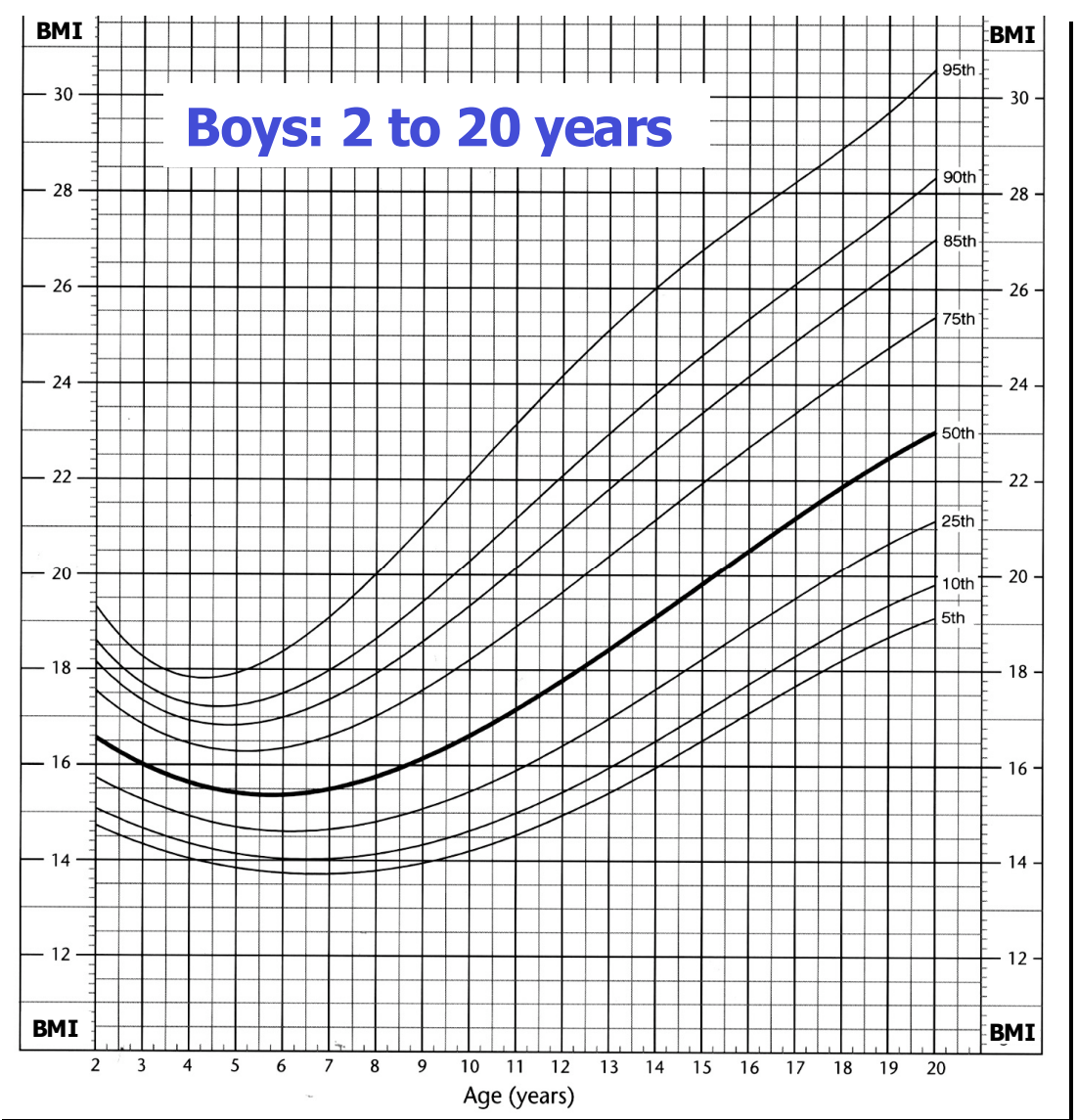

\section{Figure 1: A BMI chart}

The BMI growth chart is a good example of how a mathematical model is arbitrary but can become naturalised as the 'norm' and thus unquestioned. In this process, the model often becomes infused into a society's practices - for instance the measurement of BMI when you take out a gym membership. It is precisely due to the uncritical view of numbers and charts that mathematical models such as the BMI charts become 'black boxes'. By 'black box' here we mean weights and heights of individuals are used to calculate BMI's and compared to values on charts without considering the complex nature of the body, such as fitness level, muscle mass, bone structure, gender and ethnicity. Charts are reified (abstract but considered to be real) and their construction is often rarefied (reserved for 
an elite group or reserved to be constructed using a software package). BMI charts are constructed, arbitrary conventionalised representational forms. We have shown how they are largely treated as a line chart or a time-series chart with often a fair amount of misconception about what the lines mean.

\section{Demystifying and critiquing academic numeracy practices}

BMI charts can enable us to critically explore the academic numeracy practices of the discipline. The BMI chart can be effectively used in the classroom by, for example, getting students to use their own weights and heights to develop their own models which they can then test out. This is one way in which students can be exposed to the arbitrary nature of the mathematical models that are employed and allow a debate about what is 'ideal' or 'normal' and the assumptions underlying the BMI model as a 'black box' can be exposed. It is important to talk through and understand the conventions for the representation of data in tables and graphical representations. It needs to be made clear that many phenomena (such as growth patterns and the diagnosis of certain illnesses) are uncertain and that the chance of uncertain events can be quantified using empirical data.

We also need to interrogate with students the rhetorical uses of graphical representations. Charts can be used as argument, as an explanatory tool, as evidence, as decoration or as a reference. The rhetorical purpose depends on the context since charts are used by a range of audiences, including medical practitioners, doctors, nurses, parents from differing educational and socio-economic backgrounds. They are also used in diverse contexts, such as clinics and homes. Charts can be used to develop an understanding of the context in which the graphical representation is situated and how graphical representations can be used to interpolate, to extrapolate, to reference (what is) and to point to a standard (what should be). The rhetorical function of a chart in a certain context often leads to particular representational choices. It is also worth pointing out to students how representational choices are influenced by the intentions of the producers, or what Kress would call the 'interest' (2003) of the signmakers and the purpose to which the information is to be put.

\section{Conclusions}

This paper has presented a New Literacies Studies approach to teaching and theorising academic numeracy in Higher Education, emphasising the situated and multimodal nature of these practices. This approach emphasises the need to recognise ways of negotiating numerical graphical information as resources for generating meaning. We have proposed the term 'academic numeracy practices' in order to emphasise the socially situated nature of all practices, to avoid thinking of a set of discrete 
skills that one can either possess or lack, and to avoid extending the characteristics of the written mode to other modes. This involves being aware and critical of the uses made of different modes. Arguments made with symbols and charts tend to be more highly valued than those made with words in certain disciplines, but also in popular discourses where they are used to legitimise information. Particular practices, including knowledge-making ones within disciplines, become part of the everyday, implicit life routines of the individual and of social institutions. Thinking of academic numeracy practices as socio-historically situated, such as the arbitrary nature of the BMI ratio, draws attention to the contested nature of dominant conventions. In order to be able to operate as critical readers and citizens, we need to interrogate the truth and authority claims made by specific mathematical representations in published texts, and examine how these work.

\section{References}

Archer, Arlene (2006) Change as Additive: Harnessing students' mutimodal semiotic resources in an engineering curriculum, Thesen, $\mathrm{L}$ and van Pletzen, E, eds, Academic Literacies and Languages of Change, Continuum, London, pp 224-251.

Archer, Arlene, Frith, Vera, and Prince, Robert (2002) A Project-Based Approach to Numeracy Practices at University Focusing on HIV /AIDS, in Literacy and Numeracy Studies, vol 11, no 2, pp 123-131.

Ascher, Marcia (1991) Ethnomathematices, A Multicultural View of Mathematical Ideas, Brooks/Cole Publishing Company, California.

Ascher, Marcia and Ascher, Robert (1986) Ethnomathematics, in History of Science 24, pp 125-144.

Barton, D and Hamilton, M (1998) Local Literacies: A Study of Reading and Writing in One Community, Routledge, New York.

Baynham, Mike (1995) Literacy Practices. Investigating literacy in social contexts, Longman, London and New York.

Baynham, Mike and Baker, Dave (2002) 'Practice' in Literacy and Numeracy Research: Multiple perspectives, in Ways of Knowing Fournal vol 2, no 1, pp 1-9.

Bezemer, Jeff and Kress, Gunther (2008) Writing in multimodal texts. A social semiotic account of designs for learning, Written Communication, vol 25, no 2, pp 166-195.

Bourdieu, Pierre (1977) Outline of a Theory of Practice, translated by Nice, R, Cambridge University Press, Cambridge.

Chapman, Anne and Lee, Alison (1990) Rethinking Literacy and Numeracy. Australian Fournal of Education, vol 34, no 3, pp 277-289. 
Chouliaraki, Lilie and Fairclough, Norman (1999) Discourse in Late Modernity. Rethinking Critical Discourse Analysis, Edinburgh University Press, Edinburgh.

Coben, Diana (2003) Adult Numeracy: Review of research and related literature, National Research and Development Centre for Adult Literacy and Numeracy, Institute of Education, London.

D'Ambrosio, Ubiratan (1997) Ethnomathematics and its Place in the History and Pedagogy of Mathematics, in Powell, Arthur B and Frankenstein, Marilyn, eds, Ethnomathematics. Challenging Eurocentrisim in Mathematics Education, State University of New York, New York.

Department of Education (2003) National Curriculum Statement Grades 10-12 (General) Mathematics, Government Printer, Pretoria.

Fitzsimons, Gail, Coben, Diana and O'Donoghue, John (2003) Lifelong Mathematics Education, in Bishop, AJ, Clements, MA, Keitel, C, Kilpatrick, J, Leung, FKS, eds, Second International Handbook of Mathematics Education, Kluwer Academic Publishers, Dordrecht, pp 103-142.

Gal, Iddo, van Groenestijn, Mieke, Manly, Myrna, Schmitt, Mary Jane and Tout, Dave (2005) Adult Numeracy and its Assessment in the ALL Survey: A Conceptual Framework and Pilot Results, in Scott, Murray, T, Clermont, Yvan and Binkley, Marilyn, eds. International Adult Literacy Survey Measuring Adult Literacy and Life Skills: New frameworks for assessment, Statistics Canada, Ottawa, Canada, pp 137-191.

Gee, James (1996) Social Linguistics and Literacies: Ideology in Discourses. 2nd edition, Falmer Press, London.

Heath, Shirley-Bryce (1983) Ways with Words, Cambridge University Press, Cambridge, UK.

Hughes-Hallett, Deborah (2001) Achieving Numeracy: The challenge of implementation, in Steen, Lyn Arthur, ed, Mathematics and Democracy, The Case for Quantitative Literacy. The National Council on Education and the Disciplines, USA, pp 93-98.

Jablonka, Eva (2003) Mathematical Literacy, in Bishop, AJ, Clements, MA, Keitel, C, Kilpatrick, J, Leung, FKS, eds, Second International Handbook of Mathematics Education, Kluwer Academic Publishers, Dordrecht.

Kress, Gunther (2000) Multimodality, in Cope, Bill and Kalantzis, Mary, eds, Multiliteracies. Literacy Learning and the Design of Social Futures, Routledge, London and New York.

Kress, Gunther (2003) Literacy in the New Media Age, Routledge, London and New York.

Kress, Gunther and Van Leeuwen, Theo (1996) Reading Images. The grammar of visual design, Routledge, London.

New London Group (1996) A Pedagogy of Multiliteracies: Designing Social Futures, Harvard Educational Reviewe, vol 66, no 1, pp 60-92. 
Powell, Arthur B and Frankenstein, Marilyn, eds (1997) Ethnomathematics. Challenging Eurocentrisim in Mathematics Education, State University of New York, New York.

Prince, Robert and Archer, Arlene (2006) Quantitative Literacy as situated social practice in Higher Education, International Fournal of Learning, Common Ground Publishers, vol 12, no 7, pp 227-234.

Quetelet, Lambert Adolphe Jacques (1969) A Treatise on Man and the Development of his Faculties, Scholar's Facsimiles and Reprints, USA.

Roth, Wolff-Michael and Bowen, G. Michael (2001) Professionals read graphs: A semiotic analysis, Fournal for Research in Mathematics Education, vol 32, no 2, pp 159-194.

South Africa Department of Education National Curriculum Statement Grades 10-12 (General), South African Government.

Stein, Pippa (2003) Rights, Representation and Resources: Multimodal communication in South African classrooms, Unpublished $\mathrm{PhD}$ thesis, University of the Witwatersrand.

Street, Brian (1984) Literacy in Theory and Practice, Cambridge University Press, Cambridge.

Street, Brian (1995) Social Literacies: Critical approaches to literacy in development, ethnography and education, Longman, London and New York.

Street, Brian (2000) Literacy Events and Literacy practices, in Martin-Jones, $\mathrm{M}$ and Jones, K, eds, Multilingual Literacies. Reading and writing different worlds, John Benjamins Publishing Company, Amsterdam, Philadelphia.

Street, Brian (2005) Applying New Literacy Studies to Numeracy as Social Practice, in Rogers, Alan, ed, Urban Literacy: Communication, identity and learning in development contexts, Institute for Education, London.

Street, Brian and Baker, Dave (2006) So, What About Multimodal numeracies?, in Roswell, Jennifer and Pahl, Kate, eds (2006) Travel Notes from the New Literacy Studies, Multilingual Matters Ltd, Cleveden, Buffalo, Toronto.

Street, Brian, Baker, Dave and Tomlin, Alison (2002) Home and School Numeracy Practices: Where are the borders and overlaps?, in Valero, Paolo and Skovsmose, Ole, eds, Proceedings of the $3^{\text {rd }}$ International MES Conference, Copenhagen: Centre for Research in Learning Mathematics, pp 1-10.

Street, Brian, Rogers, A. and Baker, Dave (2006) Adult Teachers as Researchers: Ethnographic approaches to Numeracy and literacy as Social Practices in South Asia, Convergence, XXXIX, 1, pp 31-44

Swain, Jon, Baker, Elizabeth, Holder, Deborah, Newmarch, Barbara and Coben, Diana (2005) 'Beyond the Daily Application': Making numeracy teaching meaningful to adult learners, National Research and Development Centre for Adult Literacy and Numeracy, Institute of Education, London. 
